\title{
The Comparison of Three Fast Screening Methods for RO Scale Inhibitors
}

\author{
Maodong $\mathrm{Li}^{1, \mathrm{a}}$, Mengsha $\mathrm{Hu}^{2, \mathrm{~b}}$, Lin Yang ${ }^{1, \mathrm{c}}$, Juan Liu ${ }^{1, \mathrm{~d}}$, Jiaqiang Wei ${ }^{2, \mathrm{e}}$ and \\ Baiqing Zhou ${ }^{2, \mathrm{f}}$ \\ ${ }^{1}$ Guangzhou Special Pressure Equipment Inspection and Research Institute, Guangzhou 510663, \\ China \\ ${ }^{2}$ Wuhan University, Wuhan 430072, China \\ aLmd92791@21cn.com, bmengs1486@126.com, cyang79123@126.com, djuanl1010@163.com, e \\ weijiaqiang20085@163.com, 'bqzhou@whu.edu.cn
}

Keywords: Reserve Osmosis; scale inhibitors; screening methods; total weighted mean value.

\begin{abstract}
This paper utilizes the conductivity method, critical $\mathrm{pH}$ method and turbidity measurement to select RO scale inhibitors. Six kinds of RO scale inhibitors both at home and abroad are used to explore feasibility of the three methods. The results show that, all of them can be the rapid screening methods for scale inhibitors; test temperature and dosage of inhibitor affect screening results. The total weighted mean value is suggested to evaluate RO scale inhibitors. And the relative standard deviation (RSD) of the conductivity method, critical $\mathrm{pH}$ method and turbidity measurement are $1.92 \%, 0.57 \%$ and $55.23 \%$ respectively.
\end{abstract}

\section{Introduction}

Reverse Osmosis has gained more and more application, which makes RO scale inhibitors more popular. According to the primary statistics, there are many brands of RO scale inhibitors and users need to select favorable RO scale inhibitors suitable to their specific water. Therefore, exploring selecting method for RO scale inhibitors possesses high practical value. At present, there are many fast selecting methods. This paper utilizes the conductivity method, critical pH method and turbidity measurement to select RO scale inhibitors, and the three methods are simply compared.

\section{Conductivity Method}

Materials. Water bath, magnetic stirrer, DDS-307 conductivity meter, DJS-1C Platinized Platinum Electrode; six kinds of RO scale inhibitors (respectively numbered $\mathrm{A}, \mathrm{B}, \mathrm{C}, \mathrm{D}, \mathrm{E}$ and $\mathrm{F}$ ); $\mathrm{CaCl}_{2}$ solution and $\mathrm{Na}_{2} \mathrm{CO}_{3}$ solution.

Methods. The $\mathrm{CaCl}_{2}$ solution containing $\mathrm{RO}$ scale inhibitors in the beaker is titrated with $\mathrm{Na}_{2} \mathrm{CO}_{3}$ solution under constant temperature and stirred uniformly. In the meantime, the conductivity(D) and the consumption volume(V) of $\mathrm{Na}_{2} \mathrm{CO}_{3}$ solution are recorded continuously until the conductivity declines dramatically; then draw the conductivity titration curves with $\mathrm{V}$ as abscissa and $\mathrm{D}$ as ordinate, solving V of the highest point of the curve(denoted by Vs). The lager the Vs is, the better the RO scale inhibitor is ${ }^{[1]}$.

Results. Fig.1 shows the conductivity titration curves of RO scale inhibitors (A F) at dosage of 4 $\mathrm{mg} / \mathrm{L}$ and temperature of $30^{\circ} \mathrm{C}$. According to the Fig.1, it can be judged that the preferential order of the scale inhibiting properties is $\mathrm{F}<\mathrm{B}<\mathrm{E}<\mathrm{D}<\mathrm{A}<\mathrm{C}$ (" $<$ ” means worse than). Table 4 shows the preferential orders of different test temperatures and doses. 

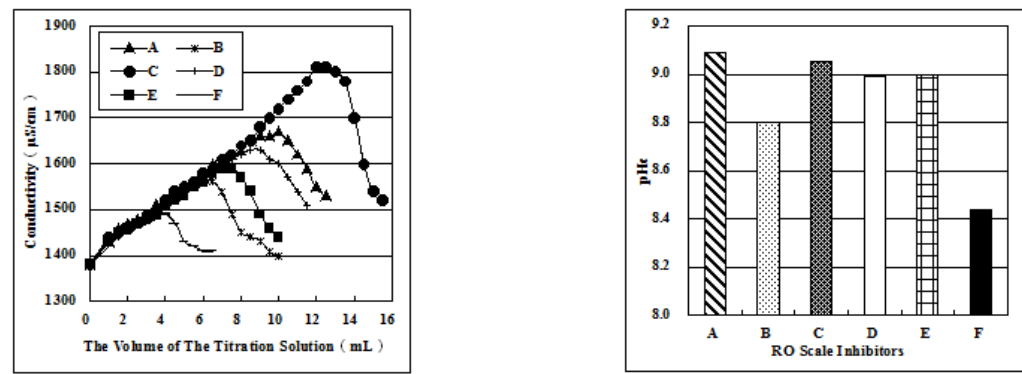

Fig. 1 the Conductivity Titration Curves

Fig. 2 the pHc of RO Scale Inhibitors

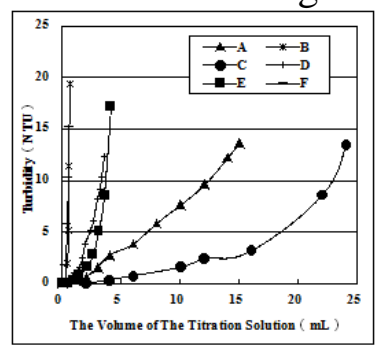

Fig. 3 the Turbidity Titration Curves

\section{Critical pH Method}

Materials. Water bath, magnetic stirrer, pHS-3C precise $\mathrm{pH}$ instrument, E-201-C $\mathrm{pH}$ composite electrode; $\mathrm{RO}$ scale inhibitors $(\mathrm{A} \sim \mathrm{F}) ; \mathrm{CaCl}_{2}$ solution, $\mathrm{NaHCO}_{3}$ solution and $\mathrm{NaOH}$ solution.

Methods. The $\mathrm{CaCl}_{2}$ and $\mathrm{NaHCO}_{3}$ solution containing $\mathrm{RO}$ scale inhibitors in the beaker is titrated by $\mathrm{NaOH}$ solution under constant temperature and stirred uniformly. In the meantime, $\mathrm{pH}$ and the consumption volume( $\mathrm{V}$ ) of $\mathrm{NaOH}$ solution are recorded continuously until $\mathrm{pH}$ declines dramatically; then draw the $\mathrm{pH}$ titration curves with $\mathrm{V}$ as abscissa and $\mathrm{pH}$ as ordinate, solving $\mathrm{pH}$ of the highest point of the curve(denoted by $\mathrm{pH}_{\mathrm{c}}$ ); the lager the $\mathrm{pH}_{\mathrm{c}}$ is, the better the RO scale inhibitor is ${ }^{[2]}$.

Results. Fig.2 shows the $\mathrm{pH}_{\mathrm{c}}$ of $\mathrm{RO}$ scale inhibitors $(\mathrm{A} \sim \mathrm{F})$ at dosage of $4 \mathrm{mg} / \mathrm{L}$ and temperature of $30^{\circ} \mathrm{C}$. According to the Fig.2, it can be judged that the preferential order of the scale inhibiting properties is $\mathrm{F}<\mathrm{B}<\mathrm{D}<\mathrm{E}<\mathrm{C}<\mathrm{A}$. Table 4 shows the preferential orders of different test temperatures and doses.

\section{Turbidity Measurement}

Materials. Water bath, GDS-3B photoelectric turbid meter, RO scale inhibitors (A F); $\mathrm{NaHCO}_{3}$ solution and $\mathrm{CaCl}_{2}$ solution.

Methods. The $\mathrm{NaHCO}_{3}$ solution containing RO scale inhibitors in the beaker is titrated by $\mathrm{CaCl}_{2}$ solution under constant temperature condition. In the meantime, turbidity $(\mathrm{N})$ and the consumption volume (V) of $\mathrm{CaCl}_{2}$ solution are recorded until turbidity increases dramatically; then draw the turbidity titration curves with $\mathrm{V}$ as abscissa and $\mathrm{N}$ as ordinate, the rising point of the curve represents the crystallization point. The later the crystallization point is, the better the RO scale inhibitor is ${ }^{[3]}$.

Results. Fig. 3 shows the turbidity titration curves of RO scale inhibitors $(A \sim F)$ at dosage of 4 $\mathrm{mg} / \mathrm{L}$ and at temperature of $30^{\circ} \mathrm{C}$. According to the Fig.3, it can be judged that the preferential order of the scale inhibiting properties is $\mathrm{F} \approx \mathrm{B}<\mathrm{D}<\mathrm{E}<\mathrm{A}<\mathrm{C}$. Table 4 shows the preferential orders of different test temperatures and doses.

\section{Method Comparison}

Reproducibility. Conductivity Method. The reproducibility test of the conductivity method is conducted at temperature of $23.4^{\circ} \mathrm{C}$, with $3 \mathrm{mg} / \mathrm{L}$ Scale Inhibitor E. Table 1 is the results of five repetition tests. The repetition RSD is $1.92 \%$, showing that the reproducibility of the conductivity method is good. 
Table 1 the Reproducibility Test of Conductivity Method

\begin{tabular}{ccccccc}
\hline \multirow{2}{*}{ Order Number } & \multicolumn{7}{c}{ The Reproducibility Test } & \multirow{2}{*}{ RSD (\%) } \\
& 1 & 2 & 3 & 4 & 5 & \\
\hline VS(mL) & 14.50 & 14.00 & 14.50 & 14.50 & 14.00 & 1.92 \\
\hline
\end{tabular}

Critical $\mathrm{pH}$ Method. The reproducibility test of the critical $\mathrm{pH}$ method is conducted at temperature of $40.0^{\circ} \mathrm{C}$, with $3 \mathrm{mg} / \mathrm{L}$ Scale Inhibitor E. Table 2 is the results of five repetition tests and the repetition RSD is $0.57 \%$, showing that the reproducibility of the critical $\mathrm{pH}$ method is very good.

Table 2 the Reproducibility Test of Critical pH Method

\begin{tabular}{ccccccc}
\hline \multirow{2}{*}{ Order Number } & \multicolumn{6}{c}{ The Reproducibility Test } \\
& 1 & 2 & 3 & 4 & 5 & \multirow{2}{*}{ RSD (\%) } \\
\hline pHC & 8.56 & 8.66 & 8.59 & 8.54 & 8.63 & 0.57 \\
\hline
\end{tabular}

Turbidity Measurement. The reproducibility test of the turbidity measurement is conducted at temperature of $24.4^{\circ} \mathrm{C}$, with $3 \mathrm{mg} / \mathrm{L}$ Scale Inhibitor E. Table 3 is the results of four repetition tests and the repetition RSD is $55.23 \%$, showing that the reproducibility of the turbidity measurement is bad.

Table 3 the Reproducibility Test of Turbidity Measurement

\begin{tabular}{cccccc}
\hline $\begin{array}{c}\text { Order Number } \\
\text { Volume of CaCl2(mL) }\end{array}$ & 1 & $\begin{array}{c}2 \\
\text { Turbidity/NTU }\end{array}$ & & RSD (\%) \\
\hline 0.40 & 0.50 & 0.00 & 0.20 & 0.30 & 83.27 \\
0.60 & 0.60 & 0.20 & 0.40 & 0.50 & 40.18 \\
1.50 & 2.20 & 0.50 & 0.60 & 1.20 & 69.38 \\
2.00 & 2.60 & 1.30 & 0.80 & 1.80 & 47.24 \\
3.00 & 3.40 & 5.80 & 1.80 & 3.50 & 45.41 \\
4.00 & 4.90 & 12.60 & 6.50 & 6.40 & 44.90 \\
5.00 & 5.80 & 21.90 & 9.70 & 11.50 & 56.24 \\
Average Value & \multicolumn{7}{c}{-} & & 55.23 \\
\hline
\end{tabular}

Summary. All of the three methods show that test temperature and dosage of inhibitor affect the results of evaluation, therefore, when using these methods, tests cannot be limited in the specific condition (for example, at temperature of $30^{\circ} \mathrm{C}$ and dosage of $4 \mathrm{mg} / \mathrm{L}$ ), and different conditions should be taken into account to hunt more information for comprehensive evaluation of scale inhibiting properties.

To get the comprehensive evaluation, we make the score of the scale inhibitor (A F) in the Table 4 are respectively 75, 80, 85, 90, 95 and 100 (the score of the best one is 100 and the worst one is 75) according to the performance of scale inhibitors. Then take the average of the scores in each selecting method, which is named the total weighted mean value, and the results are shown in the Table 5(total weighted mean value of each scale inhibitor is shown in the bracket).

There are few differences among conductivity method, critical $\mathrm{pH}$ method and turbidity measurement, but all of them show that Scale Inhibitor A and Scale Inhibitor C are relatively superior, while Scale Inhibitor B and Scale Inhibitor F are relatively worse. Therefore, all of them can be the preliminary screening methods for RO scale inhibitors.

The possible reasons for the differences exacting among the three methods are as follow:

Different Principles. Conductivity method bases on conductible ions in the solution, critical $\mathrm{pH}$ method bases on $\mathrm{H}^{+}$and turbidity measurement bases on precipitated crystal.

Different Test Conditions. For example, stirring method and rate. In conductivity method and critical $\mathrm{pH}$ method, constant speed stirring with the magnetic stirrer is included in the condition, while turbidity measurement is with manual stirring.

Different Sensitivity. When occurring little precipitation, the turbid meter can timely reflect the phenomenon, but conductivity meter and $\mathrm{pH}$ instrument cannot, in other words, turbidity measurement is more sensitive.

Table 6 is about the comparison of the three methods. 
Table 4 Performance Ranking of RO Scale Inhibitors

\begin{tabular}{|c|c|c|c|c|c|c|}
\hline \multicolumn{2}{|c|}{ Temperature $\left({ }^{\circ} \mathrm{C}\right)$ Dosage $(\mathrm{mg} / \mathrm{L})$} & \multicolumn{5}{|c|}{$\begin{array}{l}\text { The Preferential Order of The Scale Inhibiting Properties } \\
\text { Conductivity Method Critical pH Method Turbidity Measurement }\end{array}$} \\
\hline \multirow{3}{*}{20} & 2 & \multicolumn{2}{|c|}{$\mathrm{B}<\mathrm{F}<\mathrm{C} \approx \mathrm{E}<\mathrm{D}<\mathrm{A}$} & \multicolumn{2}{|c|}{$\mathrm{F}<\mathrm{B}<\mathrm{D}<\mathrm{E}<\mathrm{A}<\mathrm{C}$} & $\mathrm{B}<\mathrm{F}<\mathrm{E}<\mathrm{D}<\mathrm{C}<\mathrm{A}$ \\
\hline & 4 & \multicolumn{2}{|c|}{$\mathrm{F}<\mathrm{B} \approx \mathrm{E}<\mathrm{C}<\mathrm{A}<\mathrm{D}$} & \multicolumn{2}{|c|}{$\mathrm{F}<\mathrm{B}<\mathrm{D}<\mathrm{E}<\mathrm{A}<\mathrm{C}$} & $\mathrm{F}<\mathrm{B}<\mathrm{E}<\mathrm{D}<\mathrm{C}<\mathrm{A}$ \\
\hline & 6 & \multicolumn{2}{|c|}{$\mathrm{E}<\mathrm{F}<\mathrm{B}<\mathrm{C}<\mathrm{A}<\mathrm{D}$} & \multicolumn{2}{|c|}{$\mathrm{F}<\mathrm{D}<\mathrm{B}<\mathrm{E}<\mathrm{A}<\mathrm{C}$} & $\mathrm{F}<\mathrm{B}<\mathrm{D}<\mathrm{E}<\mathrm{C}<\mathrm{A}$ \\
\hline \multirow{3}{*}{30} & 2 & \multicolumn{2}{|c|}{$\mathrm{F}<\mathrm{B} \approx \mathrm{E}<\mathrm{D}<\mathrm{A}<\mathrm{C}$} & \multicolumn{2}{|c|}{$\mathrm{F}<\mathrm{B}<\mathrm{A} \approx \mathrm{E}<\mathrm{D}<\mathrm{C}$} & $\mathrm{F}<\mathrm{B}<\mathrm{D}<\mathrm{E}<\mathrm{A}<\mathrm{C}$ \\
\hline & 4 & \multicolumn{2}{|c|}{$\mathrm{F}<\mathrm{B}<\mathrm{E}<\mathrm{D}<\mathrm{A}<\mathrm{C}$} & \multicolumn{2}{|c|}{$\mathrm{F}<\mathrm{B}<\mathrm{D}<\mathrm{E}<\mathrm{C}<\mathrm{A}$} & $\mathrm{F} \approx \mathrm{B}<\mathrm{D}<\mathrm{E}<\mathrm{A}<\mathrm{C}$ \\
\hline & 6 & \multicolumn{2}{|c|}{$\mathrm{F}<\mathrm{B}<\mathrm{E}<\mathrm{D}<\mathrm{C}<\mathrm{A}$} & \multicolumn{2}{|c|}{$\mathrm{F}<\mathrm{B}<\mathrm{D}<\mathrm{E}<\mathrm{A}<\mathrm{C}$} & $\mathrm{F}<\mathrm{B}<\mathrm{D}<\mathrm{E}<\mathrm{A}<\mathrm{C}$ \\
\hline \multirow{3}{*}{40} & 2 & \multicolumn{2}{|c|}{$\mathrm{F}<\mathrm{D} \approx \mathrm{E}<\mathrm{B}<\mathrm{C}<\mathrm{A}$} & \multicolumn{2}{|c|}{$\mathrm{F}<\mathrm{B}<\mathrm{E}<\mathrm{A}<\mathrm{D}<\mathrm{C}$} & $\mathrm{F} \approx \mathrm{B}<\mathrm{E}<\mathrm{D}<\mathrm{A}<\mathrm{C}$ \\
\hline & 4 & \multicolumn{2}{|c|}{$\mathrm{F}<\mathrm{B}<\mathrm{E}<\mathrm{D}<\mathrm{A}<\mathrm{C}$} & \multicolumn{2}{|c|}{$\mathrm{F}<\mathrm{B}<\mathrm{D} \approx \mathrm{E}<\mathrm{A}<\mathrm{C}$} & $\mathrm{F} \approx \mathrm{B}<\mathrm{E}<\mathrm{D}<\mathrm{A}<\mathrm{C}$ \\
\hline & 6 & \multicolumn{2}{|c|}{$\mathrm{F}<\mathrm{B}<\mathrm{E}<\mathrm{D}<\mathrm{A}<\mathrm{C}$} & \multicolumn{2}{|c|}{$\mathrm{F}<\mathrm{B}<\mathrm{E}<\mathrm{D}<\mathrm{A}<\mathrm{C}$} & $\mathrm{F}<\mathrm{B}<\mathrm{D}<\mathrm{E}<\mathrm{A}<\mathrm{C}$ \\
\hline \multicolumn{7}{|c|}{ Table 5 the Comprehensive Sequencing of RO Scale Inhibitors } \\
\hline \multicolumn{2}{|c|}{ Methods } & \multicolumn{5}{|c|}{ Results } \\
\hline \multirow{2}{*}{\multicolumn{2}{|c|}{$\begin{array}{l}\text { Conductivity Method } \\
\text { Critical pH Method }\end{array}$}} & \multicolumn{5}{|c|}{$\mathrm{F}(76.1)<\mathrm{B}(81.1)<\mathrm{E}(84.4)<\mathrm{D}(91.7)<\mathrm{C}(95.0)<\mathrm{A}(96.7)$} \\
\hline & & \multicolumn{5}{|c|}{$\mathrm{F}(75.0)<\mathrm{B}(80.6)<\mathrm{D}(87.2)<\mathrm{E}(88.9)<\mathrm{A}(93.9)<\mathrm{C}(99.4)$} \\
\hline Turbidity Me & asurement & \multicolumn{5}{|c|}{$\mathrm{F}(75.6)<\mathrm{B}(79.4)<\mathrm{D}(87.2)<\mathrm{E}(87.8)<\mathrm{A}(96.7)<\mathrm{C}(98.3)$} \\
\hline \multicolumn{7}{|c|}{ Table 6 the Comparison of the Three Methods } \\
\hline Methods & \multicolumn{2}{|c|}{ Conductivity Method } & \multicolumn{2}{|c|}{ Critical pH Method } & \multicolumn{2}{|c|}{ Turbidity Measurement } \\
\hline Cost & Low & & & & & Low \\
\hline Operation & Simple & & & & & Complex \\
\hline Consuming Time & $20 \sim 40 \mathrm{mi}$ & & $15 \sim$ & $\min$ & & $60 \sim 90 \mathrm{~min}$ \\
\hline $\begin{array}{l}\text { Influence } \\
\text { Factors }\end{array}$ & $\begin{array}{l}\text { Air(CO2) and } \\
\text { rate }\end{array}$ & stirring & $\begin{array}{r}\operatorname{Air}(\mathrm{CO} 2) \\
\mathrm{r}\end{array}$ & ad stirring & Waiti & $\begin{array}{l}\text { time and volume of } \\
\mathrm{CaCl} 2\end{array}$ \\
\hline Reproducibility & Good & & Very & sood & & Bad \\
\hline Sensitivity & Bad & & & & & Good \\
\hline
\end{tabular}

\section{Conclusions}

All of the conductivity method, critical $\mathrm{pH}$ method and turbidity measurement can be the preliminary screening methods for RO Scale Inhibitors. Although using these methods could get different evaluation results, Scale Inhibitor A and Scale Inhibitor $\mathrm{C}$ are screened out by all of them.

The reproducibility of critical $\mathrm{pH}$ method is best, and the turbidity measurement is worst. If turbidity measurement is chosen, the reproducibility test must be done. Test temperature and dosage of inhibitor affect scale inhibition effect or evaluation results. The total weighted mean value of a series of tests is suggested to evaluate RO scale inhibitors. Conductivity method, critical pH method and turbidity measurement are all static screening methods, offering such advantages as simple device, easy operation, low investment and low cost, and they are suitable for rapid screening for massive RO scale inhibitors. However, test condition of static screening methods has large difference with the real conditions in a production environment, so dynamic evaluation approach should be done on the basis of static screening methods to study the practical effect of RO scale inhibitors.

\section{References}

[1] Zhu Liwei, Cao Qiuyang. Laboratory research of the assessment method for RO inhibitor[J], Industrial Water Treatment, 2008, 28(7): p. 56-73.

[2] Zhang Qing, Wu Wenhui. The application of critical $\mathrm{pH}$ value to scale inhibitor investigation[J], Industrial Water Treatment, 1997, 17(1): p. 33-34.

[3] Nie Zhouli, Wu Yumin, Zhang Jun, Wan Guangmin, Xu Jun, Liang Changjuan. Evaluation methods of scale inhibitor[J], Applied Chemical Industry, 2011, 40(5): p. 875-887. 